\title{
Recognition of the Saint Vincent and the Grenadines Red Cross Society
}

\author{
CIRCULAR No. 553
}

Geneva, 14 November 1989

\author{
To the Central Committees of the National \\ Red Cross and Red Crescent Societies
}

Ladies and Gentlemen,

We have the honour of informing you that the Saint Vincent and the Grenadines Red Cross Society has been officially recognized by the International Committee of the Red Cross. This recognition, which took effect on 4 October 1989, brings to 149 the number of National Societies that are members of the International Red Cross and Red Crescent Movement.

Founded on 15 July 1949 as a branch of the British Red Cross, the Society officially applied for recognition by the International Committee of the Red Cross on 6 March 1989. In support of its application, it forwarded various documents, including a report on its activities, the text of its Statutes and a copy of Act No. 13 incorporating the Society. This Act was adopted by Parliament on 12 April 1984 and signed into law by the Governor-General on 17 May 1984. It attests that the Society is recognized by the Government as a voluntary aid society auxiliary to the public authorities in accordance with the provisions of the First Geneva Convention of 1949.

These documents, which were examined jointly by the International Committee of the Red Cross and of the Secretariat of the League of Red Cross and Red Crescent Societies, showed that the ten conditions for recognition by the ICRC of a new National Society may be considered as fulfilled.

The progressive development of the Saint Vincent and the Grenadines Red Cross Society, has been closely observed by the ICRC and the League and their representatives have visited the Society several times in recent years. They have ascertained that the Society has a sound infrastructure which enables it to extend its activities throughout the national territory. These activities are being 
developed in several spheres: first-aid training, social assistance for the elderly and the destitute, disaster preparedness and emergency aid to disaster victims.

On 1 April 1981, the Swiss Federal Council received notification of the accession by Saint Vincent and the Grenadines to the Geneva Conventions of 12 August 1949, which entered into force in that country on 1 October 1981.

On 8 April 1983, Saint Vincent and the Grenadines furthermore deposited an instrument of accession to the two Protocols of 8 June 1977 additional to the said Conventions. The Protocols entered into force there on 8 October 1983.

The Director General of the Saint Vincent and the Grenadines Red Cross Society is Mrs. Yvonne Patterson. The headquarters is located in Kingstown at the following address: Saint Vincent and the Grenadines Red Cross Society, P. O. Box 431.

The International Committee of the Red Cross has pleasure in welcoming the Saint Vincent and the Grenadines Red Cross Society to membership of the International Red Cross and Red Crescent Movement, in accrediting it and commending it, by this circular, to all other National Societies, and in expressing sincere good wishes to the Society for its future and for the success of its humanitarian work.

\author{
FOR THE INTERNATIONAL COMMITTEE \\ OF THE RED CROSS \\ Cornelio Sommaruga \\ President
}

\title{
Course on international humanitarian law for Dutch-speaking countries
}

The Flemish Section of the Belgian Red Cross and the Netherlands Red Cross jointly organized a course on international humanitarian law for representatives from all regions where Dutch is spoken. The course, the first of its kind, was held in Bruges, Belgium, from 10 to 17 September 1989 and was attended by 38 people, including students, a professor, dissemination officers, trainee diplomats and representatives of various ministries from the Netherlands, Flanders, Indonesia and Suriname.

Opening remarks were made by Mr. Daniel Coens, Minister of Education of the Flemish Community, Mr. J. J. van der Weel, President of the Netherlands Red Cross and Mr. V. Leysen, President of the Belgian Red Cross 